\title{
SEASONAL MIGRATION PATTERN OF OWLS AT BUKOWO-KOPAŃ STATION (N POLAND) IN 2000-2003
}

\author{
Damiana Michalonek, Wojciech Busse and Przemysław Busse
}

\begin{abstract}
Michalonek D.A., Busse W., Busse P. 2004. Seasonal migration pattern of owls at BukowoKopań station (N Poland) in 2000-2003. Ring 26, 1: 13-21.

Data were collected at the Operation Baltic stations and included over 2000 owls caught and ringed at Bukowo-Kopań station in autumns 2000-2003. Birds were caught with raptor nets, ringed and measured according to the Operation Baltic standards.

The Long-eared Owl (Asio otus) is the most numerous migrant at Polish coast of the Baltic Sea. Migration of this species has wave-like pattern with few nights of very high owl numbers after nights without these birds. Amount of migrants changes decidedly from year to year. This is a result of fluctuations associated with small mammal populations dynamics. Other owl species pass Bukowo-Kopań station in rather low numbers. We can distinguish two groups of owl species according to terms of passage peaks. Both the Short-eared Owl (Asio flammeus) and the Barn Owl (Tyto alba) migrate in the highest numbers generally at the same time as the Long-eared Owl, i.e. at the beginning of November. Correlation is in most cases statistically significant. On the contrary, the migration pattern of the Tengmalm's Owl (Aegolius funereus) is conspicuously different. Passage maximum of this species occurs at the beginning of October and by 25 October the passage is almost finished. But even then individuals that migrate later are caught during the same migration peaks as the Long-eared Owl.

Obtained results indicate that the passage of different owls is similar to the most numerous and typical migrant species - the Long-eared Owl. Other species choose the same nights for passage, which suggests that some common factors influencing owl migration exist.
\end{abstract}

D. Michalonek, W. Busse, P. Busse, Bird Migration Research Station, Univ. of Gdańsk, Przebendowo, PL-84-210 Choczewo, Poland, E-mail: michalonek@univ.gda.pl

Publication appointed to the SE European Bird Migration Network papers

Key words: owls, migration pattern, passage waves, correlation.

\section{INTRODUCTION}

Owl migration is rather poorly studied. Studies are quite complicated because of bird nocturnal activity, low number of caught and ringed individuals and small number of recoveries as a result. 
The Long-eared Owl (Asio otus) is described as migratory species in northern parts of its distribution range - in Fenno-Scandia and Russia north of $50^{\circ} \mathrm{N}$ (Mikkola 1983, Cramp and Simmons 1985, Scott 1993, Glue and Nilsson 1997), especially during severe and prolonged winters (Mikkola 1983). They move south or west (Mikkola 1983, Dobrynina 1994) and south-east (Dobrynina 1994) in winter. Further south in Europe Long-eared Owls are mostly sedentary, except for the postfledging dispersal of the young (Mikkola 1983, Cramp and Simmons 1985, Scott 1993, Glue and Nilsson 1997). The Short-eared Owl (Asio flammeus) is also migratory in northern - arctic and sub-arctic regions, while in the South it is a partial migrant. Long-distance migrations and dispersion movements undertaken outside the breeding season are typical for this nomadic owl, during some winters number of birds involved is larger than in others because of food abundance differences (Cramp and Simmons 1985, Glue and Korpimaki 1997). The Tengmalm's Owl (Aegolius funereus) is mostly nomadic (northern populations), except for adult males, which show year-round site tenacity. In Central Europe both sexes show stronger breeding site fidelity (Cramp and Simmons 1985, Korpimaki 1997). Young birds disperse widely and probably they can predominate in intensive movements occurring in some years (Cramp and Simmons 1985). Migrating individuals fly not so far as the Long-eared Owls but generally in the same direction (Dobrynina 1994). The Barn Owl (Tyto alba) and the Tawny Owl (Strix aluco) are mainly sedentary species except for the young, which similarly to other owl species disperse from the birth place (Cramp and Simmons 1985, Osieck and Shawyer 1997, Petty and Saurola 1997, Soufflot et al. 2003). In particular the Barn Owl shows strong tendency to wide natal dispersion -25 percent of these owls ringed as nestlings in southern Germany were reported from distance of over $100 \mathrm{~km}$ from the ringing site (Berthold 1993). Ringing and recovery data from the Courish Spit show that the Barn Owl is one of the furthest migrant although it flies in north-eastern direction (Dobrynina 1994). Post-fledging dispersal starts in August (Tawny Owl) or September (Barn Owl) and is continued till November (Osieck and Shawyer 1997, Petty and Saurola 1997).

\section{MATERIAL AND METHODS}

We used data collected at the Operation Baltic stations. The data included over 2000 owls caught and ringed at Bukowo-Kopań station $\left(54^{\circ} 21^{\prime} \mathrm{N}, 16^{\circ} 17^{\prime} \mathrm{E} / 54^{\circ} 28^{\prime} \mathrm{N}\right.$, $16^{\circ} 25^{\prime} \mathrm{E}$ ) in autumns $2000-2003$. Birds were caught using special raptor nets (i.e. with mesh size of $45-80 \mathrm{~mm}$ ), which were opened 24 hours a day (Busse and Busse 2003). Owls were ringed and measured according to the Operation Baltic standards (Busse and Kania 1970).

Data from years 1961-2003 were used to prepare long-term dynamics of each caught owl species. Data were smoothed by moving average to present general pattern and to emphasise trends.

Detailed analysis of seasonal migration pattern was done on 2000-2003 data as the number of birds (especially Short-eared Owls, Tengmalm's Owls and Barn Owls) was high enough to enable such analysis. 
The Long-eared Owl seasonal migration pattern was given for each year as a chart based on daily catching numbers. These charts were basis to the analysis of correlation between other owl species and the Long-eared Owl migration. Days when no owl were caught were excluded. Pearson's correlation coefficient $(r), z$-test and statistical significance were calculated for pairs: the Long-eared Owl as independent variable and each of other species as dependent variable. These parameters were calculated for two periods: from 11 October to 16 November for each pair and additionally for other periods in years when time of migration was different.

\section{RESULTS AND DISCUSSION}

\section{General pattern of owl migration}

In some years there are more migrants than in others (Table 1). This is a result of fluctuations associated with small mammal populations dynamics (Cramp and Simmons 1985, Scott 1993). High breeding success of owls during seasons when rodents are abundant may result in the increase of passage intensity of birds after prey number crushed, which was observed for many owls species (the Long-eared Owl, the Short-eared Owl, the Tengmalm's Owl and even the Barn Owl).

Table 1

Number of owls caught at Bukowo-Kopań station in autumns 2000-2003

\begin{tabular}{|l|r|r|r|r|r|}
\hline & 2000 & 2001 & 2002 & 2003 & Total \\
\hline Asio otus & 610 & 202 & 736 & 190 & $\mathbf{1 7 3 8}$ \\
\hline Asio flammeus & 33 & 49 & 45 & 41 & $\mathbf{1 6 8}$ \\
\hline Tyto alba & 15 & 13 & 12 & 15 & $\mathbf{5 5}$ \\
\hline Aegolius funereus & 19 & 16 & 12 & 7 & $\mathbf{5 4}$ \\
\hline Strix aluco & 4 & 3 & 3 & 1 & $\mathbf{1 1}$ \\
\hline Total & $\mathbf{6 8 1}$ & $\mathbf{2 8 3}$ & $\mathbf{8 0 8}$ & $\mathbf{2 5 4}$ & $\mathbf{2 0 2 6}$ \\
\hline
\end{tabular}

The Long-eared Owl starts autumn migration at Polish coast of the Baltic Sea about 20 September, but the highest peaks occur in October and first half of November (Busse and Busse 2003). Similar pattern was observed at Biological Station "Rybachy" of the Zoological Institute of the Russian Academy of Sciences on the Courish Spit (Belopolsky 1974). Such migration pattern probably depends on weather conditions, moon phase and other factors (Busse and Busse 2003).

The Long-eared Owl migration dynamics patterns in seasons 2000-2003 are shown in Figure 1. It is known that the Long-eared Owl migration has wave-like pattern with few nights of very high owl numbers after nights with very low passage intensity (Belopolsky 1974, Busse and Busse 2003). In autumn a few peaks are characteristic for the Long-eared Owl. It is interesting that the most distinctive peak at 

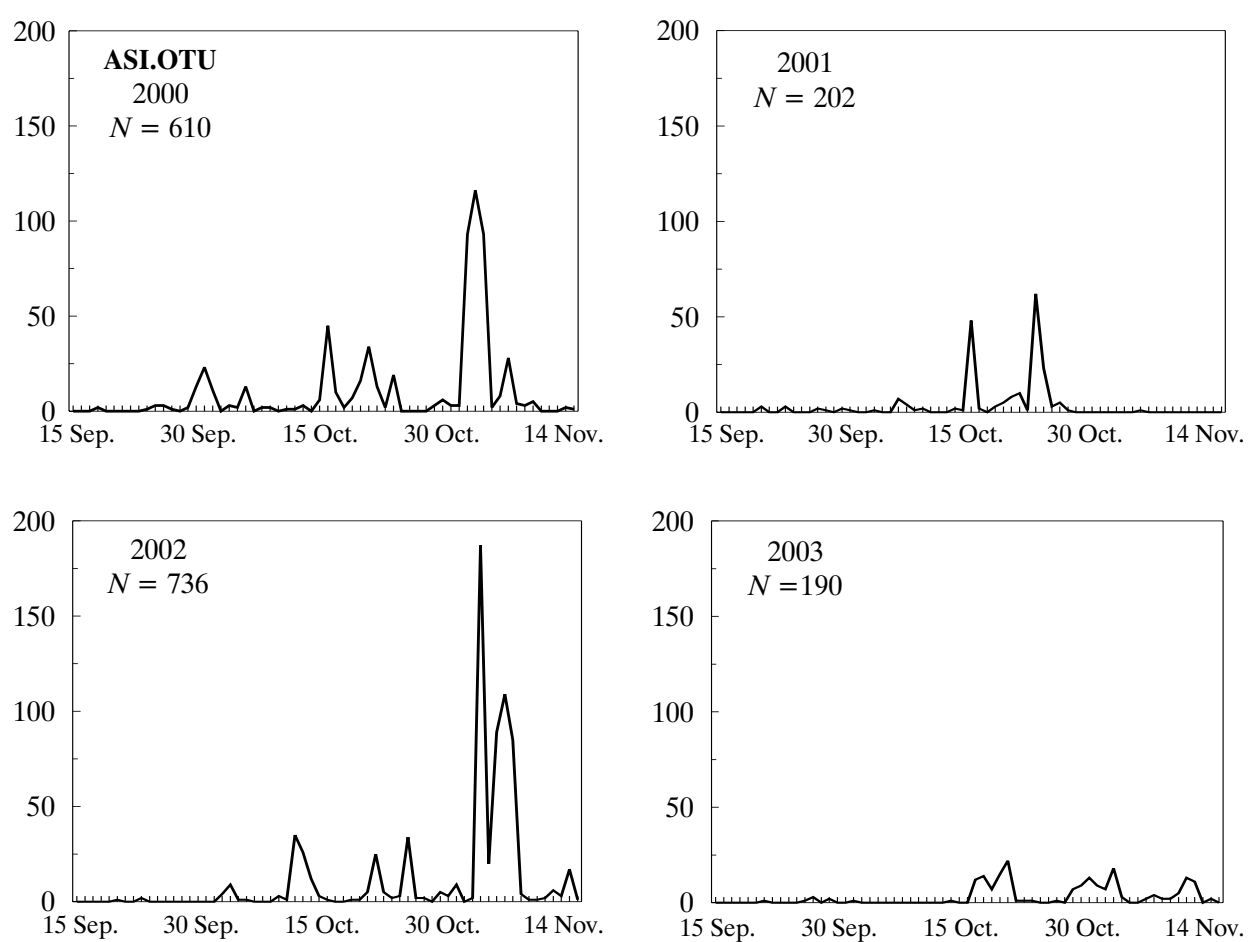

Fig. 1. Seasonal migration pattern of the Long-eared Owl (ASI.OTU)

the beginning of November is well pronounced in years when large number of owls pass Bukowo-Kopań station (in 2000 - 610, in 2002 - 736 individuals caught), whilst in years with low number of owls (in 2001 - 202, in 2003 - 190 individuals caught) this peak is lacking. This may depend on breeding success, weather conditions and food availability on breeding grounds. Probably it could be correlated with age and sex structure of migrating birds. Further studies are necessary.

The general migration dynamics (pooled for seasons 1961-2003) of all studied species are given in Figure 2. It is possible to distinguish two groups of owl species according to terms of passage peaks. Both the Short-eared Owl and the Barn Owl are most numerous in the same time as the Long-eared Owl, i.e. at the beginning of November but they start migration earlier and the number of passing birds is not concentrated in one peak only - it is more uniform throughout the whole season. In particular the Short-eared Owl shows more "smooth" passage in all autumns with frequent peaks starting from the beginning of September. On the contrary, migration pattern of the Tengmalm's Owl is conspicuously different. Passage maximum of this species occurs at the beginning of October and by 25 October the passage is almost finished. We did not observe second peak at the beginning of November as at the Courish Spit (Dobrynina 1994), although Bukowo-Kopań ringing station was working during the first half of this month. 

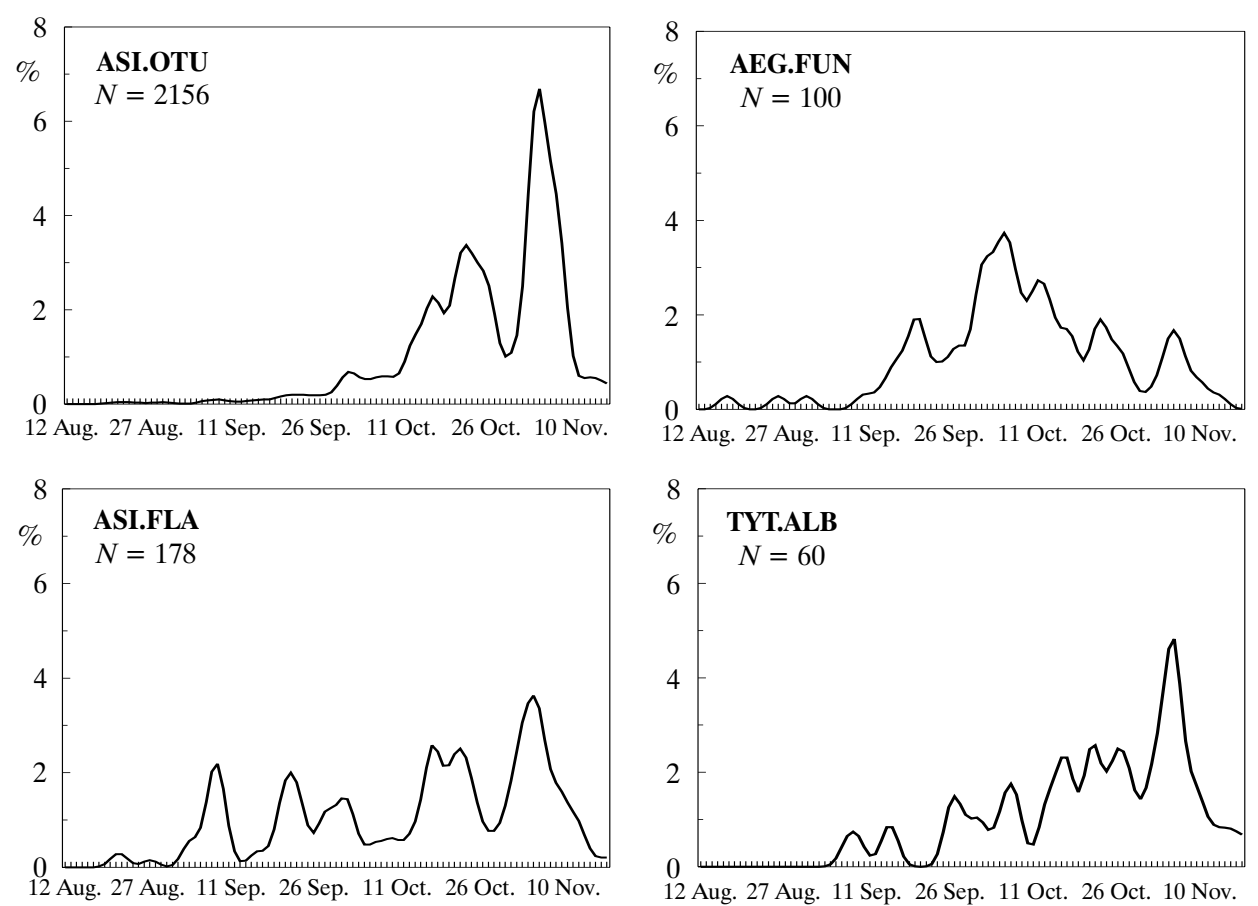

Fig. 2. General autumn migration dynamics patterns (pooled for seasons 1961-2003) of owls: the Long-eared Owl (ASI.OTU), the Tengmalm's Owl (AEG.FUN), the Short-eared Owl (ASI.FLA), the Barn Owl (TYT.ALB). Smoothed by running average.

\section{Correlation between the Long-eared Owl and other owl species migration pat- terns}

Occurrences of Tengmalm's Owls, Short-eared Owls, Barn Owls and Tawny Owls in comparison to the passage of Long-eared Owls are shown in Figure 3. Relations between correlation coefficients are listed in Table 2 .

Table 2

Correlation between the Long-eared Owl and other owl species migration at Bukowo-Kopań station in the standard period (11 Oct. - 16 Nov.);

$r$-correlation coefficient, $z$ - test, $p$ - statistical significance

\begin{tabular}{|c|c|c|c|c|c|c|c|c|c|c|c|c|}
\hline & \multicolumn{2}{|c|}{ Aegolius funereus } & \multicolumn{4}{|c|}{ Asio flammeus } & \multicolumn{4}{c|}{ Tyto alba } & \multicolumn{3}{c|}{ Strix aluco } \\
\cline { 2 - 14 } & $r$ & $z$ & $p$ & $r$ & $z$ & $p$ & $r$ & $z$ & $p$ & $r$ & $z$ & $p$ \\
\hline 2000 & $\mathbf{0 . 6 5}$ & 3.52 & 0.001 & $\mathbf{0 . 6 1}$ & 3.29 & 0.01 & $\mathbf{0 . 4 9}$ & 2.58 & 0.05 & $\mathbf{0 . 6 1}$ & 3.25 & 0.01 \\
\hline 2001 & -0.09 & -0.37 & $n s$ & $\mathbf{0 . 5 4}$ & 2.17 & 0.05 & 0.43 & 1.68 & $n s$ & - & - & - \\
\hline 2002 & $\mathbf{0 . 4 1}$ & 2.41 & 0.05 & $\mathbf{0 . 5 0}$ & 2.90 & 0.01 & $\mathbf{0 . 6 0}$ & 3.44 & 0.001 & $\mathbf{0 . 5 4}$ & 3.12 & 0.01 \\
\hline 2003 & $\mathbf{0 . 5 3}$ & 2.65 & 0.01 & $\mathbf{0 . 5 2}$ & 2.59 & 0.05 & 0.05 & 0.27 & $n s$ & - & - & - \\
\hline
\end{tabular}



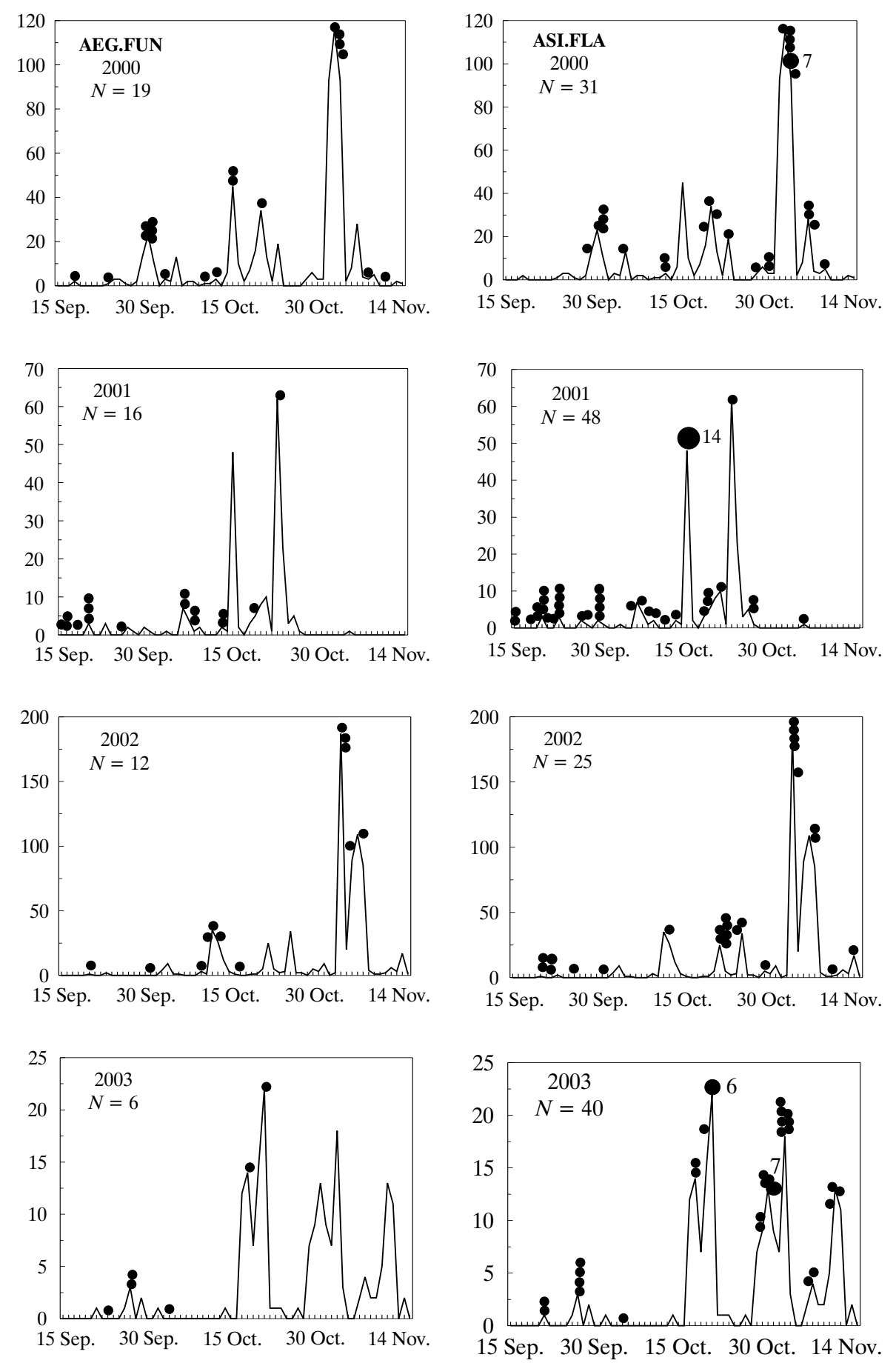

Fig. 3. Location of the Tengmalm's Owl (AEG.FUN), the Short-eared Owl (ASI.FLA), the Barn Owl (TYT.ALB) and the Tawny Owl (STR.ALU) records (dots) in relation to the Long-eared Owl (ASI.OTU) passage pattern in autumns 2000-2003 

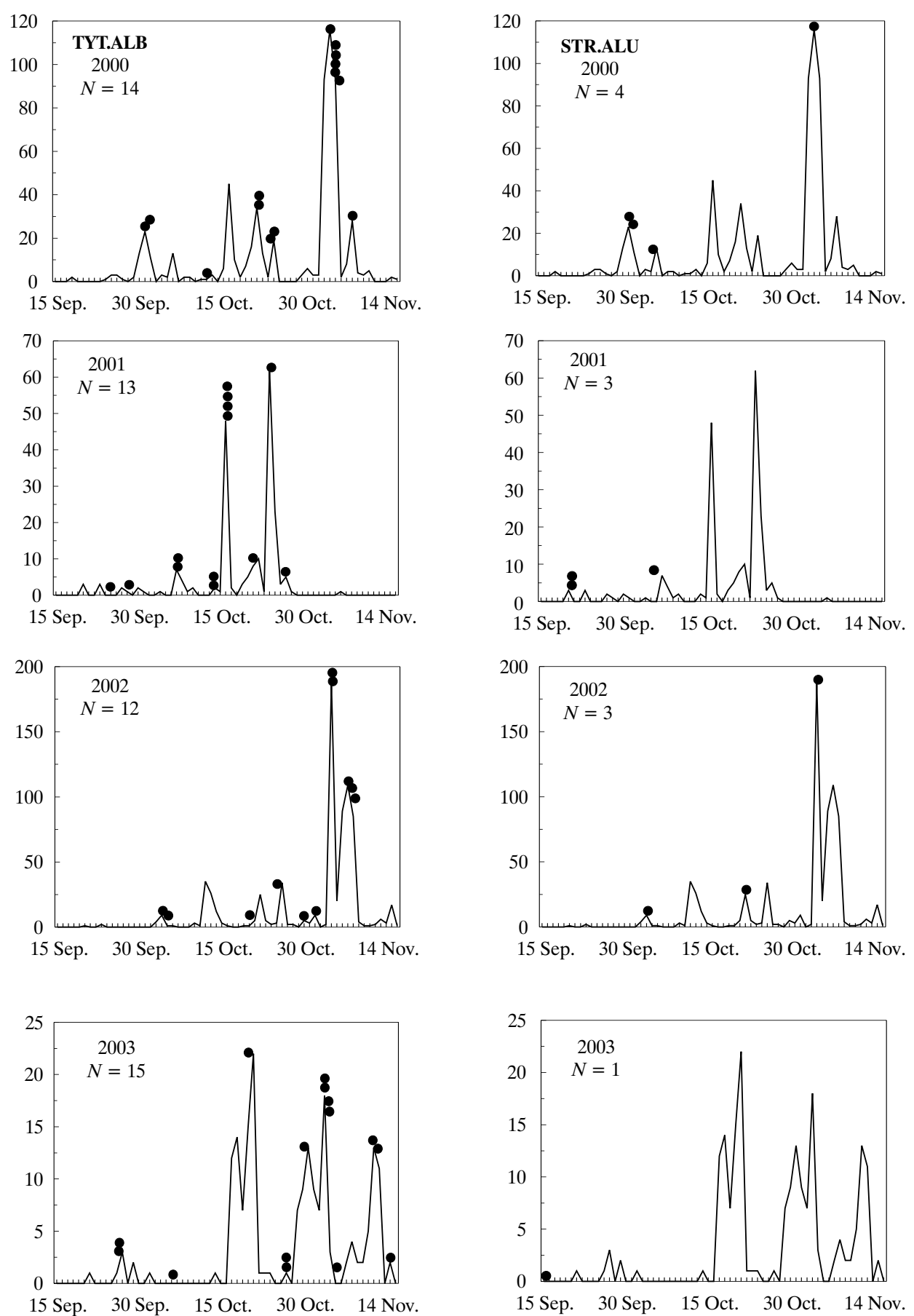
The Tengmalm's Owl generally starts migration earlier than the Long-eared Owl and its passage maximum takes place earlier as well. It seems there is no correlation in passage of both species, but if we take under consideration shorter period when both species are present (i.e. 11 October -16 November), there is a statistically significant correlation in years 2000, 2002 and 2003 - it could mean that the Tengmalm's Owl migrates on the same days as the Long-eared Owl does during migration period common for both species.

The Short-eared Owl starts migration earlier than the Long-eared Owl but for the migration period common for both species (11 October - 16 November) the passage of them is quite well correlated - correlation coefficient reaches more than $0.6(2000)$ and $0.5(2001,2002,2003)$ and is statistically significant in all seasons.

The Barn Owl and the Long-eared Owl migrate generally in the same time - but correlation for the standard period is statistically significant in autumn 2000 and 2002 only. In autumn 2001 the time of passage of both species differed very much from other seasons and it was necessary to consider correlation in really common migration period (i.e. 6 October -28 October). For this period correlation coefficient was very high (over 0.8 ) and statistically significant $(p<0.001$ ). In 2003 migration of the Barn Owl was rather asynchronous, but still most of individuals of this species migrated in peak days of the Long-eared Owl migration.

Numbers of Tawny Owls were too low to draw a conclusion but it is worth to note the correlation in years 2000 and 2002. Every individual was caught exactly on days when the Long-eared Owl was numerous.

The obtained results indicate that the passage of different owls is similar to the most numerous and typical migrant species - the Long-eared Owl. This suggests that some common factors influencing owl migration exist. One of them may be the weather but further studies are necessary. Weather conditions affect strongly owl activity, especially hunting. Strong winds and heavy rain can stop the Long-eared Owls from hunting or they can use "sit and wait" method then (Mikkola 1983). It is possible that bad weather could influence migration as well, because: (1) it seems that at least some owls hunt on passage (they are caught not high over ground 0.5-4 m); (2) in our opinion owl feather structure causes birds to avoid "moist conditions", i.e. rain and fog, as these feathers get wet easily and this restrains normal flight ability.

\section{REFERENCES}

Belopolsky L. 1974. Migration peculiarities of some species of owls (Strigiformes) on the basis of trapping and ringing data obtained on the Courland Spit in 1957-1968. Commun. Baltic Comm. Stud. Bird Migr. 8: 51-71.

Berthold P. 1993. Bird Migration: a general survey. Oxford Univ. Press, Oxford: pp. 37-38.

Busse P., Busse W. 2003. Autumn migration of owls along Polish Baltic coast 1961-1999. Vogelwelt 140, 6.

Busse P., Kania W. 1970. Operation Baltic 1961-1967. Working methods. Acta orn. 12, 7: 251-267.

Cramp S., Simmons K.E.L. (Eds). 1985. The Birds of the Western Palearctic. Handbook of the Birds of Europe, the Middle East and North Africa. vol. 4. Oxford Univ. Press, Oxford. 
Dobrynina I.N. 1994. Seasonal movements of owls (Strigiformes) in the Baltic region based on ringing data. Ring 16, 1-2: 77-83.

Glue D., Korpimaki E. 1997. Short-eared Owl. In: Hagemeijer W.J.M. and Blair M.J. (Eds). The EBCC Atlas of European Breeding Birds: their Distribution and Abundance. T \& A D Poyser, London: pp. 418-419.

Glue D., Nilsson I.N. 1997. Long-eared Owl. In: Hagemeijer W.J.M. and Blair M.J. (Eds). The EBCC Atlas of European Breeding Birds: their Distribution and Abundance. T \& A D Poyser, London: pp. 416-417.

Korpimaki E. 1997. Tengmalm's Owl. In: In: Hagemeijer W.J.M. and Blair M.J. (Eds). The EBCC Atlas of European Breeding Birds: their Distribution and Abundance. T \& A D Poyser, London: pp. 420-421. Mikkola H. 1983. Owls of Europe. Buteo Books, Vermillion, South Dakota: pp. 211-232.

Osieck E., Shawyer C. 1997. Barn Owl. In: Hagemeijer W.J.M. and Blair M.J. (Eds). The EBCC Atlas of European Breeding Birds: their Distribution and Abundance. T \& A D Poyser, London: pp. 398-399.

Petty S. J., Saurola P. 1997. Tawny Owl. In: Hagemeijer W.J.M. and Blair M.J. (Eds). The EBCC Atlas of European Breeding Birds: their Distribution and Abundance. T \& A D Poyser, London: pp. 410-411.

Scott D. 1993. The Long-eared Owl. The Zoological Society of London.

Soufflot J., Soufflot P., Baudvin H. 2003. Informations Fournies par les Controles de Chouettes Effraies Tyto alba en Bourgogne. Alauda 71, 2: 191-200. 